\title{
Wilderness Canoeing in Ontario: Using Cumulative Results to Update Dichotomous Choice Contingent Valuation Offer Amounts
}

\author{
Kimberly Rollins \\ Department of Agricultural Economics and Business, Ontario Agricultural College, \\ University of Guelph, Guelph, Ontario.
}

Received 4 October 1995, accepted 16 January 1997

\begin{abstract}
This study used cumulative results to update the distributions from which offer amounts were drawn in a dichotomous choice contingent valuation of user benefits from wilderness canoeing in Ontario's wilderness parks. An empirical model demonstrates the efficiency gains from using this procedure. Results allow comparison of variation in average daily willingness to pay (WTP) by trip length, indicating decreasing average benefits per trip-day. Two payment vehicles were used. Canoeists indicated ranges of WTPs which conformed to expected hypotheses when the payment vehicle was an increase in general trip costs. However, the same respondents indicated an upper bound on WTP when the payment vehicle was an increase in the provincial park backcountry permit price.
\end{abstract}

Cette étude s'appuie sur les résultats cumulatifs d'une valuation contingente à choix dichotomique pour mettre à jour les distributions parmi lesquelles ont été établies les bénéfices pour les usagers du canoeing sauvage dans les parcs de l'Ontario. Un modèle empirique démontre les gains efficients de l'application de ce processus. Les résultats permettent de comparer la variation des sommes moyennes qu'on veut bien payer selon la longueur du voyage, et indiquent des bénéfices moyens décroissants par journée de voyage. Deux véhicules de paiement ont été utilisés. Les canoeurs ont indiqué une gamme de sommes qu'ils voulaient bien payer conforme aux hypothèses lorsque le véhicule de paiement était une augmentation $d u$ coût total du voyage. Toutefois, les mêmes répondants indiquaient une limite supérieure dans les sommes qu'ils voulaient bien payer quand le véhicule de paiement représentait une augmentation du prix du permis de camping sauvage du parc provincial.

\section{INTRODUCTION}

The objective of this paper is to demonstrate empirically how using cumulative results from returned surveys to update contingent valuation offer amounts can improve the efficiency of estimates, to demonstrate empirically the effect of alternative payment vehicles on estimates, and to report estimated levels of benefits that accrue to backcountry canoeists. A single-bounded dichotomous choice contingent valuation model is used to measure maximum willingness to pay (WTP) per canoeing day for canoeists using Ontario provincial park wilderness areas.
This study is performed in anticipation of provincially mandated decisions to augment the provincial parks' operating budgets partly through an increase in user fees.

The next section of the paper reviews current methods of choosing dichotomous choice contingent valuation bid amounts. A methods section follows, which describes questionnaire design and survey procedures used in the study. The third section presents the estimated logit models. Results are presented and discussed in the following section. The final section summarizes conclusions and draws policy implications. 


\section{Selection of CVM Bid Amounts: Background Discussion}

A typical dichotomous choice (DC) contingent valuation method (CVM) questionnaire asks survey respondents whether they would participate in some recreational activity (or vote to change the level of provision of some public good) if it were to cost the respondents $\$ X$. The $\$ \mathrm{X}$ bid amount offered to any given respondent is randomly chosen from a predetermined set of bid amounts distributed over the survey sample. The respondent answers either Yes or No. The analysis typically assumes that the probability of a No response increases with increasing offer amounts according to a logistic distribution. Surplus benefits are measured as willingness to pay (WTP) for the good in question and are calculated using the parameters of the estimated logit.

It has long been a topic of concern that the efficiency of welfare estimates derived using the dichotomous choice CVM depends on the specific choice of $\$ X$ bid amounts drawn from a prior estimate of a true distribution of WTP; the choice of sample size, $N$; and on the choice of how $N$ is allocated over the bid amounts. In the first major work that addresses this question, Duffield and Patterson (1991) developed a nonparametric tool to optimally allocate a given set of bid amounts over a sample size chosen to meet a specified confidence interval goal. They demonstrated that their method to allocate bid amounts outperformed an earlier method used by Boyle et al (1988), which selects bid amounts uniformly distributed over a wide range of the hypothesized underlying distribution, extending well into the tails of the distribution. Duffield and Patterson's approach depends on two pieces of critical information that are taken as given: a preliminary estimate of the willingness to pay distribution, and a given set of bid amounts drawn from this distribution. They also tested the robustness of welfare estimates by deleting bid amounts at the tails of the distribution and concluded that welfare estimates are very sensitive to bid amounts and are potentially biased.

Kanninen and Kriström (1993) pointed out that bid values in the tails of the distribution are highly influential because they increase the variances of the willingness to pay estimates. They further showed that, provided that the distribution is correctly specified and that the change in sample size is corrected for, dropping bids in the extreme tails should increase the efficiency of the willingness to pay estimators. They suggested that perhaps an equally important concern researchers must consider is whether the underlying distribution of WTP has been correctly identified. They showed that, theoretically, unbiased estimates of WTP can be obtained from almost any range of bid values, and posited that the issue of optimal bid design is one of efficiency.

Cooper (1993) built on Duffield and Patterson's work by developing a model that simultaneously selects optimal bid amounts, sample size and distribution of the sample over the bid amounts. The criterion for the optimal experimental design is that with the lowest mean squared error of the expected willingness to pay, based on prior information on the underlying distribution of willingness to pay. Alberini (1995) defined a more general optimization problem in which the objective function is a specified measure of the efficiency of the chosen WTP measure. Alberini's general approach is able to consider alternative models including single-bounded, doublebounded and bivariate response models.

While these estimation methods have greatly improved upon selection of bid amounts and sample size with regard to the efficiency of welfare estimates, they all rely upon prior information on the underlying distribution. The frustrating reality that faces applied CVM work is that the underlying distribution is rarely known with certainty prior to the selection of bid amounts. The Cooper and Alberini methods to produce more efficient estimators typically do so by using a relatively narrow range of bid amounts. Because variance is inversely proportional to sample size on each bid amount, the more efficient designs tend to have smaller numbers of bid amounts clustered more closely toward the median of the distribution, relative to the earlier approach of Boyle et al. If the true underlying distribution is different from the hypothesized distribution, the researcher producing data using these methods designed to 
minimize variance would be less able to recover a better estimate of the true distribution. On the other hand, the Boyle et al approach, while perhaps not as efficient, provides more insurance against this dilemma by including a broader range of bid amounts.

Cooper (1993, p. 39) acknowledged:

An implicit underlying theme is that quality pretest information is necessary for the construction of a good sampling plan. At best, the researcher should produce a small run of preliminary surveys that ask open-ended versions of the planned DC CVM questions.

Open-ended pretests are recommended because they are less expensive to carry out, with each observation containing more information than the binary Yes or No response of a DC respondent. However, empirical studies have shown that typically open-ended estimates of WTP are, in general, significantly different from estimates derived from dichotomous choice responses. Further, there is little certainty that the distribution of WTP under an open-ended pretest will be the same as that under a DC response task. Finally, in more recent years, the debate between the reliability of open-ended versus DC form of CVM questions has significantly tended to favor the use of the latter for a variety of reasons (Arrow et al 1993).

A problem that warrants further exploration is an efficient means of determining a reasonable prior estimate of the underlying distribution while also choosing optimal bid design for the DC CVM. It is for this reason that one of the objectives of this paper is to suggest a method of improving information on the underlying distribution, so that existing methods to determine optimal bid designs can be better applied.

\section{PROCEDURES FOR THE CVM STUDY}

\section{Definition of the "Good"}

A decision to define the "good" as a backcountry trip of two or more nights was made early in the study. Park staff had pointed out that the backcountry areas offer two types of trip experiences (goods). The experience offered by the outer edges of a backcountry area is qualitatively different from that offered by the interior. Day users and campers who camp for one night only see the more congested edge areas that are most easily accessible. Since the good of interest is a backcountry wilderness canoe trip, it was decided that it would be desirable to exclude day users, hikers and single-night campers. This was easy to do since all backcountry canoeists must purchase their permits prior to their trip and must indicate a trip plan and the number of nights they plan to be in the interior.

\section{Contingent Valuation Questions}

The study used single-bounded dichotomous choice elicitation procedures in a mail-back survey of backcountry canoeists in Ontario, using the three main provincial wilderness canoe destinations. In a format standard for DC CVM, participants were asked whether they would take the same canoe trip in the provincial park in which they received the questionnaire if it were to cost them $\$ \mathrm{X}$ more than the personal expenditures they actually paid. Two different payment vehicles were used for this question. The first was an increase in all trip costs, including the backcountry user fee, travel costs, equipment rental costs and so forth. The second vehicle was an increase in the backcountry user fee alone; at the time of the study, the 1993 canoe season, the fee was $\$ 4.25$ per person per day, identical for each of the three sites. The study also gathered information to estimate a variety of travel cost models, as a means of reliability testing.

After reminding survey participants of tradeoffs involved with protecting wilderness areas and the importance of realistic answers to contingent valuation questions, participants were asked whether they would take the same canoe trip the next year ${ }^{1}$ if the total cost to them increased by a specified amount. They had already been asked to provide a breakdown of their total trip costs (travel, food, fuel, outfitters fees, permit costs). The precise breakdown of the hypothetical increase in the cost per trip was not specified. The "increase in total trip costs" question read: 
In [an earlier question] you told us what it cost you to take this trip. Suppose that canoeing and camping conditions are roughly similar to those for the trip on which you received this questionnaire, with one exception:

\section{* Your costs in 1994 will be \$ what you paid in 1993. \\ higher than}

Under these conditions, would you still go on this canoe trip in 1994? (Circle one number).

1 NO

2 YES, I WOULD STILL GO ON THIS CANOE TRIP UNDER THESE CONDITIONS.

Over the five months, increased trip costs inserted in the corresponding blanks ranged from $\$ 20$ to $\$ 300$, according to the procedure outlined below. An earlier question had asked each about the length of the trip in days, so that the analysis could proceed on a value per trip-day basis.

A second question asked the same respondents whether they would pay a given price for a backcountry permit (on a per-person-day basis) to maintain the current level of wilderness quality in the park. The "increase in permit price" question read:

The current provincial park interior camping fee is $\$ 4.25$ per person per day. What would be the maximum daily Interior Camping Permit fee you would pay before you would accept a reduction in park quality?

\section{* Would you pay \$__ for an Interior Camping Permit Fee? (Circle Yes or No)}

1 NO

2 YES

For this question, the permit prices inserted in the corresponding blanks ranged from $\$ 6$ to $\$ 25$ per person per day.

\section{Survey Procedures and Sampling Strategy} During the months of June through October 1993, trained park staff handed out the survey to canoeists taking trips of two or more nights in three parks as the participants pur- chased their backcountry camping permits at the start of their trips. Participants were asked to fill out the questionnaire soon after their trips, and then to return them in the supplied postage-paid envelopes. Algonquin, Killarney and Quetico provincial parks in Ontario were chosen because they represent the most heavily used and largest provincially owned wilderness canoeing sites in Ontario. The sampling period for each park ended on the dates of the seasonal closures for each park. These dates were September 6, for Quetico provincial park, and October 11 for Algonquin and Killarney provincial parks. The overall usable response rate was $88 \%$, for a total of 2,434 usable surveys collected.

These parks vary by the degree of crowding, proximity to urban areas, size, number of canoe routes, amount of advance time required for reservation booking, and landscape features. Killarney park is smallest $\left(485 \mathrm{~km}^{2}\right)$, has a low interior camping quota and therefore often has long trip reservation lists. Algonquin park $\left(7,725 \mathrm{~km}^{2}\right)$ has the largest quotas, but is under the greatest use pressure due to its proximity to the large urban centers of Ottawa and Toronto. Quetico park $\left(4,655 \mathrm{~km}^{2}\right)$ offers the greatest degree of solitude and virtually no waiting period due to its large size and remote location.

The sampling scheme, based on visitor statistics from the 1992 season, was stratified by park, park entry point and month. The questionnaire included a form with the participant's name and address, forwarded by park staff to the researchers on a weekly basis. The form was used for later identification of nonrespondents and of randomly drawn "prize winners" for an assortment of sponsor-donated recreational equipment. Reminder cards were sent to nonrespondents three weeks after their forms arrived from the parks. Three weeks after that, nonrespondents were sent a second copy of the survey with a covering letter explaining the importance of their participation in this survey. A total of three followup mail contacts were issued to nonrespondents. As a final prompt, nonrespondents were contacted by phone and asked to return their survey. Approximately 50 survey partic- 
ipants were not contacted because either their form was not returned by the park, the address on the form was illegible or repeated attempts to locate them were unsuccessful.

\section{Selection of Bid Amounts for Contingent Valuation Questions}

The wilderness canoeing study provided a unique opportunity to sequentially adjust bid amounts as estimates of the underlying distribution were updated each month. The survey sample design called for the sample to be stratified by month. Questionnaires were distributed to wilderness users on-site at the start of their trips. The original bid amounts were determined through extensive pretesting using an open-ended format. Six offer amounts were uniformly distributed, to start with, over bid amounts that straddled the hypothesized median, extending to approximately include the 20th and the 80th percentiles. As responses were mailed back, results from returned surveys were used to adjust the distribution from which offer amounts for each CVM question were drawn each month. Three sets of adjustments, each time upward, resulted in a total of 12 bid amounts for the CVM questions over the 1993 season.

\section{WTP ESTIMATION: THE MODEL}

A utility-theoretic logit regression model (Hanneman 1984) is used to predict probabilities of No responses as functions of the offer amounts. These probabilities are used to calculate mean and median values of peoples' maximum willingness to pay. Mean and median WTPs are calculated from maximum likelihood estimates for a binomial logit model. The data set provides CVM responses for total trip values (an easier task for respondents than a direct per-day valuation task). These values are subsequently divided by trip length as reported by each respondent. Dummy variables are set up in model three below to allow trips of different lengths to be considered as different goods.

The general expression for the logit probability function can be written as:
$L_{t}=\ln (P t /(1-P t))=a+B W t$

where

$W_{t}=$ the bid amount assigned to the $i$ th canoeist

$L_{t}=$ the Yes or No response to the offer amount, indicated as 0 or 1 , respectively $P_{t}=$ the probability of a No response.

Rearranging the above expression gives the form of this relationship for the logistic regression models, in this study given by:

$$
P_{i j t}=\frac{1}{1+\exp \left(-\left(a_{i j}+B_{i j} X_{i j t}\right)\right)} \quad \begin{array}{ll}
i=2,3 \ldots 10 \\
j=1,2,3
\end{array}
$$

where $P_{i j t}$ is the probability that canoeist $t$ will answer No to an offer amount $X_{i j t}$ to participate in the same canoe trip in 1994 . For each model described below, $a_{i j}$ is the intercept and $B_{i j}$ is the slope for the $i j$ th version of the logit of $P_{i j t}$ against $X_{i j t}$.

Dummy variables for park, trip length and numbers of encounters at each trip location allow the estimated coefficients to vary by combinations of categories. Thus, $R j$ indexes the three parks $(R 1=1$ for Algonquin park and 0 otherwise; $R 2=1$ for Quetico park and 0 otherwise; $R 3=1$ for Killarney park and 0 otherwise). Similarly, $K_{i}$ indexes 14 categories of canoe trip lengths (as indicated in Tables 2 and 3). The variable $A_{t}$ is defined for a given observation $t$ as:

$$
A_{t}=\frac{\text { offer amount (dollars) }}{\text { trip length (number of days) }}
$$

The independent variable $X_{i j t}$ is defined as the offer amount expressed in dollars for a specified trip length at a particular park. In the most general case, where all parks and trip length categories are specified for observation $t$ :

$$
X_{i j t}=A_{t}^{*} K_{i}^{*} R_{j}
$$

An intercept term, $a_{i j}$, is also indexed by park and trip length.

Three models are specified for each of the "total trip cost increase" and "permit 
price increase" questions. Model 1 estimates canoeists' daily WTP value for the same canoe trip in 1994 from the combined data for all the parks. In this model, $X_{t}=A_{t}$; park and trip length categories are not used:

$$
\text { Model 1: } \quad \operatorname{Pr}\left(L_{t}=0\right)=\frac{1}{1+e^{-\left(a_{t}+B X_{t}\right)}}
$$

in which utility is represented by $U_{t}=a+$ $B X_{t}$.

Model 2 determines whether daily WTP values vary by park. Thus, $X_{j t}=A_{t} * R_{j}$ :

Model 2:

$$
\operatorname{Pr}\left(L_{t}=0\right)=\frac{1}{1+e^{-\left(\Sigma_{j=1}^{J} a_{j}+\sum_{j=1}^{J} B_{j} X_{j t}\right)}}
$$

in which utility is represented by $U_{t}=\sum_{\mathrm{j}=1}^{\mathrm{J}} a_{i}+$ $\sum_{\mathrm{j}=1}^{\mathrm{J}} B_{j} X_{j t}$.

Model 3 determines whether canoeists' daily WTP is affected by the duration of the canoe trips. Thus $X_{i t}=A_{t} * K_{i}$, and:

Model 3:

$$
\operatorname{Pr}\left(L_{t}=0\right)=\frac{1}{1+e^{-\left(\Sigma_{i=1}^{I} a_{i}+\Sigma_{i=1}^{I} B_{i} X_{i t}\right)}}
$$

in which utility is represented by $U_{t}=\sum_{i=1}^{\mathrm{I}} a_{i}+$ $\sum_{i=1}^{\mathrm{I}} B_{i} X_{i t}$

The models for the "increased permit price" question are similar to those described above for the "increase in total trip cost" question. In both cases, canoeing and camp- ing conditions are assumed to be the same, with the exception specified in the question. The variable $\hat{A}_{t}$ is defined to be the proposed price for the daily per person backcountry permit. The terms $K_{i}$ and $R_{j}$ are as defined previously, so for models 1,2 and 3 for the increased permit price question:

$$
\hat{X}_{i j t}=\hat{A}_{t} * K_{i} * R_{j}
$$

\section{LOGIT RESULTS}

Table 1 below summarizes response rates, mean trip lengths and total out-of-pocket costs incurred by respondents, by park. The target group appears to consist of committed, well-informed wilderness users. More than half include comments giving their views on the parks, park management, and how the wilderness could be better managed so that users would have less impact on the environment and on each others' enjoyment. No observations are identifiable as obvious protest bids; therefore we cannot justify deleting any of the observations as outliers. A protest bid in a discrete choice format would be one in which a respondent refuses to answer the valuation question, or answers Yes to an amount that is much higher or No to an amount that is much lower than her/his true valuation. Since the survey instrument does not include many bid values that lie on the extreme upper tails, the opportunity for a respondent to say Yes to an extremely high amount does not often present itself. Overall, only 32 respondents $(1.3 \%)$ did not respond to the valuation questions.

Table 2 presents the results of the estimated logit models for model 1 (all parks and all trip lengths combined) for both payment vehicles. Tables 3 and 4 present results for

Table 1. Survey response rates, respondents' trip costs and trip lengths by park

\begin{tabular}{lcccc}
\hline Park & $\begin{array}{c}\text { Number of returned } \\
\text { usable surveys }\end{array}$ & $\begin{array}{c}\text { Response } \\
\text { rate }\end{array}$ & $\begin{array}{c}\text { Mean length } \\
\text { of trip }\end{array}$ & $\begin{array}{c}\text { Mean of respondents' } \\
\text { total trip costs }\end{array}$ \\
\hline Quetico & & $(\%)$ & $($ days) & \\
Killarney & 1,322 & 91 & 7.7 & $\$ 740.02$ \\
Algonquin & 479 & 88 & 4.8 & $\$ 210.47$ \\
\hline
\end{tabular}


Table 2. Model 1: Willingness to pay per trip-day by payment vehicle, all trip lengths and all parks combined

\begin{tabular}{|c|c|c|c|c|}
\hline & \multicolumn{4}{|c|}{ Payment vehicle } \\
\hline & \multicolumn{2}{|c|}{ Increase in general trip costs } & \multicolumn{2}{|c|}{$\begin{array}{l}\text { Increase in backcountry } \\
\text { permit fee }\end{array}$} \\
\hline & Coefficient & Std. error & Coefficient & Std. error \\
\hline Constant $\left(a_{i j}\right)$ & $-2.2135^{*}$ & 0.0946 & $-1.8452 *$ & 0.1300 \\
\hline $\operatorname{Bid}\left(B_{i j}\right)$ & $0.0349 *$ & 0.0023 & $0.0755^{*}$ & 0.0068 \\
\hline$N$ & 2398 & & 2381 & \\
\hline Log likelihood & -1252.80 & & $-1511.91 *$ & \\
\hline Correct prediction (\%) & 74.1 & & 63.5 & \\
\hline Median WTP & $\$ 63.42$ & & $\$ 24.44$ & \\
\hline Mean WTP & $\$ 66.40$ & & $\$ 26.38$ & \\
\hline
\end{tabular}

* Significant at or above the $1 \%$ level, $\alpha=2.576$.

Table 3. Model 2: Willingness to pay per trip-day by park; payment vehicle: increase in total trip costs ${ }^{a}$

\begin{tabular}{lccccc}
\hline Park & Constant $\left(a_{i j}\right)$ & Bid $\left(B_{i j}\right)$ & $N$ & Median WTP & Mean WTP \\
\hline Algonquin & $-1.8240^{*}$ & $0.0293^{*}$ & 630 & $\$ 62.25$ & $\$ 67.37$ \\
& $(0.270)$ & $(0.0035)$ & & & \\
Quetico & $-2.5867^{*}$ & $0.0404^{*}$ & 1320 & $\$ 64.03$ & $\$ 65.82$ \\
& $(0.2588)$ & $(0.0036)$ & & & \\
Killarney & $-1.60^{*}$ & $0.0278^{*}$ & 479 & $\$ 60.65$ & $\$ 66.76$ \\
& $(0.2154)$ & $(0.0042)$ & & & \\
$N$ & & 2429 & & & \\
Log likelihood & & -1241.10 & & \\
Correct prediction $(\%)$ & & 74.2 & & \\
\hline
\end{tabular}

${ }^{a}$ Standard errors shown in parantheses.

* Significant at or above the $1 \%$ level, $\alpha=2.576$.

model 2 (WTP per trip-day by park) for "increased total trip costs" and "increased permit prices," respectively. Tables 5 and 6 present results for model 3 (WTP per trip-day by trip length) for "increased total trip costs" and "increased permit prices," respectively. The mean (and/or median) WTP values represent average surplus benefits per day received by canoeists in each model. ${ }^{2}$ Closeness of mean and median WTP estimates indicates that the distribution reaches asymptotic limits relatively quickly, reducing the area within the tails of the distribution. Mean WTP estimates are calculated to include $99.99 \%$ of the population, as estimated by each model.

\section{WTP as Measured by an "Increase in} Total Trip Costs"

Model 1 in Table 2 implies that for the canoeists surveyed, the mean WTP for the 
Table 4. Model 2: Willingness to pay per trip-day by park; payment vehicle: increase in the backcountry permit fee ${ }^{a}$

\begin{tabular}{lccccc}
\hline Park & Constant $\left(a_{i j}\right)$ & Bid $\left(B_{i j}\right)$ & $N$ & Median WTP & Mean WTP \\
\hline Algonquin & $-2.1567^{*}$ & $0.0101^{*}$ & 633 & $\$ 21.27$ & $\$ 22.35$ \\
& $(0.4606)$ & $(0.0164)$ & & & \\
Quetico & $-1.6816^{*}$ & $0.0647^{*}$ & 1322 & $\$ 25.99$ & $\$ 28.63$ \\
& $(0.4175)$ & $(0.0086)$ & & & \\
Killarney & $-2.6201^{*}$ & $0.1246^{*}$ & 479 & $\$ 21.03$ & $\$ 21.59$ \\
& $(0.3763)$ & $(0.0219)$ & & & \\
$N$ & & 2434 & & & \\
Log likelihood & & -1506.34 & & \\
Correct prediction $(\%)$ & & 57.2 & & \\
\hline
\end{tabular}

${ }^{a}$ Standard errors shown in parantheses.

* Significant at or above the $1 \%$ level, $\alpha=2.576$.

same trip is $\$ 66.40$ per person per day, over all parks combined. Model 2 results in Table 3 indicate no statistical difference between constants and coefficients for Algonquin and Killarney parks at the 5\% significance level. It is not surprising that these two parks exhibit the same probability distribution for WTP, because both parks are approximately the same distance from the same population areas where most of the park visits originate and offer similar wilderness experiences. However, there is sufficient evidence at the $5 \%$ level to support the alternative hypothesis that there is a difference in the constants and coefficients on the per-day offer amounts between Quetico and the other two parks. Quetico canoeists have a slightly lower mean WTP.

Table 1 indicates that out-of-pocket expenditures reported by Quetico respondents were on average $\$ 96.11$ per day, compared with $\$ 43.85$ and $\$ 46.26$ for canoeists in Killarney and Algonquin parks, respectively. Thus, although the net benefit for Quetico canoeists reported is lower than that for the other parks, this is due in part to the fact that Quetico visitors already pay considerably more for a canoe trip in Quetico than canoeists at Killarney or Algonquin parks. This result illustrates the site-specific nature of nonmarket surplus benefit estimates, and the potential problems that arise when policy makers, and some economists, mistakenly attempt to assign values to a site that have been obtained from another site.

\section{WTP as Measured by an "Increase in the Price of a Permit"}

Tables 2, 4 and 6 present net benefit per day received by canoeists in the different models, as estimated by WTP for increased permit prices. Model 1 in Table 2 indicates that for the canoeists surveyed, the mean WTP for a backcountry use permit is $\$ 26.38$ per person per day. Log likelihood ratio tests indicate that including constants that vary with park (model 2, Table 4) and trip length (model 3, Table 6) result in statistically significant improvements of the models at the $1 \%$ level of significance (i.e., model 1 is restricted while model 3 is the unrestricted).

Model 2 suggests that surplus benefit received by canoeists in Quetico park is significantly different, at the $5 \%$ level, from those for the other two parks. As with the 
increase in total trip cost payment vehicle, there is no significant difference between the slope and constant coefficients between Killarney and Algonquin parks. Visitors to Quetico provincial park had a mean WTP of $\$ 28.63$ per person per day compared with $\$ 22.35$ and $\$ 21.59$ per day for canoe trips in Algonquin and Killarney provincial parks, respectively.

Estimates of surplus benefits derived from the "increase in total trip costs" question and the "increase in permit price" question are considerably different. One reason is evident in some canoeists' comments that they objected to paying higher permit fees because they objected to this method of payment. That is, they rejected the payment vehicle. Many respondents commented that they considered higher permit fees unfair to those visitors with lower incomes or felt that the additional revenue from the increased permit fees would not be used to maintain the wilderness character of the park(s). Many respondents expressed concern that additional funds from higher permit fees would be used to justify park infrastructure such as visitor centers, motorhome and car campsites, and larger park bureaucracies. Some respondents had penned in next to their CVM responses that a Yes was contingent on the money being used only for wilderness protection. Additionally, canoeists may decide to canoe elsewhere or during the unregulated season in order to avoid paying the increased permit fees. In either case, it would be reasonable that WTP as measured by the increased permit price should be less than WTP as measured by total trip expense increases and that it would be less likely to vary with trip length. Model 3 illustrates that WTP based on the permit price is less sensitive to trip length or park categories, suggesting an upper bound on the amount canoeists feel they are willing to pay for the permit.

\section{WTP for a Canoeing Day, by Trip Length Categories}

Model 3 illustrates how daily WTP is affected by the length of the canoe trip. For example, Table 5 suggests that canoeists derive an estimated net benefit of $\$ 59.42$ per day for a three-day canoe trip and an average net benefit of $\$ 46.35$ per day for a nine-day canoe trip, as measured by median WTP. In general, this model suggests that the marginal benefits a paddler receives from an extra day of canoeing is worth more for a short trip than for a long trip, since the marginal value for an additional day would be expected to decrease with trip length. It must be noted that differences between WTP for different trip length categories can only approximate marginal value due to the fact that canoe trips of different duration are made for various reasons that cannot be incorporated into this model, such as vacation time restrictions and other unobservable variables. For example, the difference in benefits between trips of three and four days versus the difference between trips of six and seven days is not explained solely by the changing marginal value of a trip-day. By the same reasoning, this model does not assume that the value of the fourth day of a four-day trip is equivalent to the fourth day of a ten-day trip. ${ }^{3}$

The combined differences in the slopes and intercept values is significant in terms of the overall fit of the model. The log likelihood ratio tests indicate that the addition of daily slope and intercept dummies lead to a significant improvement in the zero-slopes chi-squared goodness-of-fit indicator between models. The zero-slopes chi-value for the likelihood for the unrestricted regression (model 1) is 344.669. The model specified with daily dummy variables (model 3 ) has a zero-slopes chi-value of 420.255. Therefore, it cannot be assumed that the value of a tripday is the same for trips of different lengths. ${ }^{4}$

\section{THE EFFICIENCY GAIN DUE TO ITERATIVE UPDATING OF OFFER AMOUNTS}

Assuming the correct functional form is used overall, any of the bid designs discussed in the literature will theoretically produce unbiased estimates (see Kanninen 1995 for a thorough elaboration of this point). ${ }^{5}$ The gain to the iterative procedure can be predicted to be in terms of efficiency of the estimates. An 
Table 5. Model 3: Willingness to pay per trip-day by trip length; payment vehicle: increase in total trip $\operatorname{costs}^{a}$

\begin{tabular}{|c|c|c|c|c|c|}
\hline Trip length & Constant $\left(a_{i j}\right)$ & $\operatorname{Bid}\left(B_{i j}\right)$ & $N$ & Median WTP & Mean WTP \\
\hline 3 days & $\begin{array}{c}-1.0637^{*} \\
(0.1784)\end{array}$ & $\begin{array}{c}0.0179 * \\
(0.0033)\end{array}$ & 339 & $\$ 59.42$ & $\$ 75.99$ \\
\hline 4 days & $\begin{array}{c}-2.1219^{*} \\
(0.3071)\end{array}$ & $\begin{array}{l}0.0386^{*} \\
(0.0051)\end{array}$ & 405 & $\$ 54.97$ & $\$ 57.90$ \\
\hline 5 days & $\begin{array}{c}-2.5983^{*} \\
(0.3443)\end{array}$ & $\begin{array}{l}0.0500^{*} \\
(0.0069)\end{array}$ & 363 & $\$ 51.97$ & $\$ 53.40$ \\
\hline 6 days & $\begin{array}{c}-2.6728^{*} \\
(0.3858)\end{array}$ & $\begin{array}{l}0.0432 * \\
(0.0084)\end{array}$ & 303 & $\$ 61.87$ & $\$ 63.42$ \\
\hline 7 days & $\begin{array}{l}-3.3630^{*} \\
(0.4356)\end{array}$ & $\begin{array}{l}0.0677^{*} \\
0.0107)\end{array}$ & 308 & $\$ 49.68$ & $\$ 50.18$ \\
\hline 8 days & $\begin{array}{l}-2.8251 * \\
(0.4332)\end{array}$ & $\begin{array}{c}0.0055^{*} \\
(0.0126)\end{array}$ & 243 & $\$ 50.63$ & $\$ 51.66$ \\
\hline 9 days & $\begin{array}{c}-3.7215^{*} \\
(0.6744)\end{array}$ & $\begin{array}{c}0.0803 * \\
(0.0207)\end{array}$ & 146 & $\$ 46.35$ & $\$ 46.64$ \\
\hline 10 days & $\begin{array}{c}-3.3404^{*} \\
(0.8416)\end{array}$ & $\begin{array}{l}0.0757 * * \\
(0.0327)\end{array}$ & 71 & $\$ 44.13$ & $\$ 44.59$ \\
\hline 11 days & $\begin{array}{c}-3.3850^{*} \\
(1.0629)\end{array}$ & $\begin{array}{c}0.0738 \\
(0.0418)\end{array}$ & 54 & $\$ 45.87$ & $\$ 46.32$ \\
\hline 12 days & $\begin{array}{l}-4.6309 * * \\
(1.8601)\end{array}$ & $\begin{array}{c}0.1173 \\
(0.0765)\end{array}$ & 42 & $\$ 39.48$ & $\$ 39.56$ \\
\hline 13 days & $\begin{array}{l}-2.4412 \\
(1.3377)\end{array}$ & $\begin{array}{c}0.0931 \\
(0.0628)\end{array}$ & 19 & $\$ 26.22$ & $\$ 27.12$ \\
\hline 14 days & $\begin{array}{l}-3.0697 \\
(1.7475)\end{array}$ & $\begin{array}{c}0.0481 \\
(0.0910)\end{array}$ & 22 & $\$ 63.82$ & $\$ 64.76$ \\
\hline 15-19 days & $\begin{array}{l}-3.2292 * * \\
(1.3986)\end{array}$ & $\begin{array}{c}0.0894 \\
(0.0844)\end{array}$ & 27 & $\$ 36.12$ & $\$ 36.55$ \\
\hline$>20$ days & $\begin{array}{l}-3.0082 * * \\
(1.4652)\end{array}$ & $\begin{array}{c}0.1982 \\
(0.1473)\end{array}$ & 20 & $\$ 15.18$ & $\$ 15.42$ \\
\hline$N$ & & 2362 & & & \\
\hline Log likelihood & & -1214.19 & & & \\
\hline Correct prediction (\%) & & 74.8 & & & \\
\hline
\end{tabular}

${ }^{a}$ Standard errors shown in parantheses.

* Significant at or above the $1 \%$ level, $\alpha=2.576$.

** Significant at the $5 \%$ level, $\alpha=1.96$. 
Table 6. Model 3: Willingness to pay per trip-day by trip length; payment vehicle: increase in backcountry permit fee ${ }^{a}$

\begin{tabular}{|c|c|c|c|c|c|}
\hline Trip length & Constant $\left(a_{i j}\right)$ & $\operatorname{Bid}\left(B_{i j}\right)$ & $N$ & Median WTP & Mean WTP \\
\hline 3 days & $\begin{array}{c}-1.4510^{*} \\
(0.2326)\end{array}$ & $\begin{array}{c}0.0614^{*} \\
(0.0155)\end{array}$ & 339 & $\$ 23.63$ & $\$ 27.06$ \\
\hline 4 days & $\begin{array}{c}-2.1664 * \\
(0.3971)\end{array}$ & $\begin{array}{c}0.0999 * \\
(0.0182)\end{array}$ & 405 & $\$ 21.69$ & $\$ 22.77$ \\
\hline 5 days & $\begin{array}{c}-1.8429 * \\
(0.4058)\end{array}$ & $\begin{array}{c}0.0732 * \\
(0.0176)\end{array}$ & 363 & $\$ 25.18$ & $\$ 27.19$ \\
\hline 6 days & $\begin{array}{c}-1.5648 * \\
(0.4478)\end{array}$ & $\begin{array}{c}0.0595^{*} \\
(0.0189)\end{array}$ & 303 & $\$ 26.30$ & $\$ 29.49$ \\
\hline 7 days & $\begin{array}{c}-1.9484 * \\
(0.4493)\end{array}$ & $\begin{array}{c}0.0762 * \\
(0.0190)\end{array}$ & 308 & $\$ 25.57$ & $\$ 27.32$ \\
\hline 8 days & $\begin{array}{c}-1.5050 * \\
(0.4696)\end{array}$ & $\begin{array}{c}0.0585^{*} \\
(0.0197)\end{array}$ & 243 & $\$ 25.73$ & $\$ 29.15$ \\
\hline 9 days & $\begin{array}{l}-1.4460 * * \\
(0.5805)\end{array}$ & $\begin{array}{l}0.0594 * * \\
(0.0261)\end{array}$ & 146 & $\$ 24.34$ & $\$ 27.90$ \\
\hline 10 days & $\begin{array}{l}-2.0813^{* *} \\
(0.8541)\end{array}$ & $\begin{array}{l}0.0858 * * \\
(0.0408)\end{array}$ & 71 & $\$ 24.26$ & $\$ 27.90$ \\
\hline 11 days & $\begin{array}{l}-2.2738 * * \\
(1.0113)\end{array}$ & $\begin{array}{c}0.0708 \\
(0.0417)\end{array}$ & 54 & $\$ 32.12$ & $\$ 33.50$ \\
\hline 12 days & $\begin{array}{l}-4.2344 * * \\
(1.3836)\end{array}$ & $\begin{array}{c}0.1736^{*} \\
(0.0635)\end{array}$ & 42 & $\$ 24.39$ & $\$ 24.48$ \\
\hline 13 days & $\begin{array}{c}-1.9140 \\
(1.9293)\end{array}$ & $\begin{array}{c}0.0931 \\
(0.0946)\end{array}$ & 19 & $\$ 20.78$ & $\$ 22.28$ \\
\hline 14 days & $\begin{array}{c}-0.04840 \\
(1.3688)\end{array}$ & $\begin{array}{c}-0.0239 \\
(0.0632)\end{array}$ & 22 & -141.67 & -143.07 \\
\hline 15-19 days & $\begin{array}{c}-0.3451 \\
(1.0170)\end{array}$ & $\begin{array}{c}0.0068 \\
(0.0505)\end{array}$ & 27 & $\$ 50.97$ & $\$ 130.06$ \\
\hline$>20$ days & $\begin{array}{c}-2.7186 \\
(2.0327)\end{array}$ & $\begin{array}{c}0.1816 \\
(0.1171)\end{array}$ & 20 & $\$ 14.97$ & $\$ 15.32$ \\
\hline$N$ & & 2362 & & & \\
\hline Log likelihood & & -1504.82 & & & \\
\hline Correct prediction (\%) & & 61.1 & & & \\
\hline
\end{tabular}

$a$ Standard errors shown in parantheses.

* Significant at or above the $1 \%$ level, $\alpha=2.576$.

** Significant at the 5\% level, $\alpha=1.96$. 
Table 7. Simulated effects of iterative updating of bid amount distribution for model 1 (all parks); payment vehicle: increase in total trip costs

\begin{tabular}{|c|c|c|c|c|}
\hline & Distribution 1 & Distribution 2 & Distribution 3 & Distribution 4 \\
\hline Constant coefficient & 2.8280 & 1.9471 & 1.8172 & 2.2969 \\
\hline Std. error & 0.1705 & 0.1501 & 0.1548 & 0.1386 \\
\hline$t$-statistic & 16.59 & 12.97 & 11.74 & 16.57 \\
\hline Bid amount coefficient & -0.0598 & -0.0292 & -0.0292 & -0.0369 \\
\hline Std. error & 0.0080 & 0.0035 & 0.0030 & 0.0031 \\
\hline$t$-Statistic & -7.422 & -8.396 & -9.731 & -12.0 \\
\hline$N$ & 1178 & 1178 & 1178 & 1178 \\
\hline $\begin{array}{l}\text { Chi-square for significance } \\
\text { of regression }\end{array}$ & 66.562 & 83.498 & 110.605 & 185.433 \\
\hline Ratio of Yes to No responses & 1014 / 164 & $822 / 356$ & $718 / 460$ & $843 / 335$ \\
\hline Median WTP & 47.31 & 66.54 & 62.13 & 62.29 \\
\hline $\begin{array}{c}\text { Krinsky and Robb 95\% } \\
\text { confidence interval }\end{array}$ & 40.80 to 59.01 & 60.20 to 76.09 & 57.51 to 67.90 & 57.43 to 68.64 \\
\hline
\end{tabular}

empirical model is developed to investigate how efficiency measures improve as the distribution of offer amounts is iteratively adjusted over the course of the survey. Four subsets of data are created from the complete data set, each with an identical number of observations, but with sequential bid amount distributions that simulate initial and subsequent updated beliefs about the true distribution of WTP. The first three subsets thus simulate what the final data set would look like, had the entire data set been collected using three different hypothesized distributions for WTP. These are denoted as distributions 1 through 3 in Table 7 below. The fourth subset of the data, denoted as distribution 4 in Table 7 , is simply created by randomly selecting from the final data set to approximate the final distribution of offer amounts but with a number of observations that allow direct comparison of standard errors. While there is overlap between the data sets, the basic point of demonstrating the magnitude of the efficiency gain is made quite well. ${ }^{6}$ By creating the subsets of the same size, degrees of freedom are constant between all regressions so that goodness of fit measures are directly comparable.

Results are reported in Table 7. A comparison of the standard errors of the estimated coefficients the constant and bid amount regressors shows that as the bid range approaches distribution 4 , standard errors on the coefficients decline. The declines in the standard errors and increased $t$-statistics are a result of increased precision in the logit regression for the underlying model for WTP.

The chi-square variables reported in Table 7 are a measure of model fitness as gauged by the deviance in the likelihood function with and without the bid amount regressor. Distribution 4 has the highest chisquare statistic indicating that the underlying population distribution of WTP is most closely approximated, with this model, by distribution 4. The improved fitness among regressions can also be seen by the "tightening" of the Krinsky and Robb confidence intervals around the estimated median WTP from each distribution. ${ }^{7}$ Distributions 3 and 4 have the smallest confidence intervals. 
Kanninen (1995) suggests that WTP can, in theory, be estimated efficiently using only one or two bid amounts placed immediately around the mean. ${ }^{8}$ The results presented in Table 7 nicely illustrate Kanninen's point. Distribution 3 has bid amounts clustered close to the estimated median daily WTP. Distribution 4 incorporates the full range of bid amounts and shows only small improvements in efficiency.

Distribution 1 systematically favors surveys from May and early June, because the lowest bid amounts used are dropped from later versions of the survey instrument. May and June trips are during blackfly season and have other features that may cause them to be of lower value. We believe that this may explain the lower WTP for distribution 1.

\section{AGGREGATE SURPLUS BENEFITS FROM WILDERNESS CANOEING IN ONTARIO PROVINCIAL PARKS}

The 1993 aggregate values of the net benefit (WTP) to backcountry canoeists for each of the three parks surveyed in this study are estimated based on model 2 results for total trip cost increases and park visitation figures from 1993. ${ }^{9}$ Aggregate values are $\$ 9,218,730$ for Algonquin park, $\$ 8,041,444$ for Quetico park and $\$ 2,373,212$ for Killarney park. It should be noted that these aggregate values are far from total use values for the parks, as all day visitors and canoeists who purchased permits for only one night are excluded. As well, this study focuses specifically on use value. It is likely that nonusers as well as users hold nonuse values for these areas. Similarly, the WTP estimates are elicited from a sample of current users only, and the aggregation is done over the population of current users, as measured by park visitor statistics. However, these aggregates do give important insight to the value of backcountry canoeing benefits at the provincial parks.

It has been strongly recommended that whenever possible, contingent valuation estimates be validated by other valuation methods (Arrow et al 1993). A zonal travel cost model performed using the same data set for
Quetico park results in an estimate of consumer surplus of $\$ 8.3$ million (Valla 1994).

\section{CONCLUSION}

Although the pretest procedures are detailed and quite thorough, had we used the original bid design, more than $50 \%$ of respondents would have been willing to pay the highest bid amount and our data would have been heavily skewed toward the lower portion of the distribution of WTP. This is not surprising, since significant differences between open-ended and dichotomous choice results are commonly reported. By adjusting the distribution from which offer amounts were drawn according to cumulative results, the standard errors of parameters are significantly improved. As can be seen by the results reported in this paper, the efficiency of estimates are quite satisfactory, allowing for estimation procedures requiring several partitions of the data set. While the iterative process to determine offer amounts does slightly increase the costs of administering the survey, the efficiency gain justifies the cost.

The WTP per day values give some indication as to how benefits would be affected if canoeists were to substitute longer trips for a greater number of shorter trips, or vice versa. This may eventually be a consideration for park managers as a way of managing the wilderness, if visitor rates increase over time. As expected, per day trip values decrease as trip lengths increase. It should be noted that the differences in estimated WTP per day by trips of different lengths do not incorporate reasons why given respondents may have chosen the trip lengths or parks they did. In other words, as with hedonic models, there is likely to be omitted relevant variables that affect preferences and a selfselection bias inherent in the data that the model cannot incorporate. Trips of different lengths represent different individuals, not responses by the same individual. Therefore, it is not quite correct to attribute the differences between WTP for trips of different lengths as solely due to decreasing marginal 
WTP for an extra day of a canoe trip. On the other hand, the differences in average WTP per day between trips of different lengths is statistically significant. One can infer from this that average WTP is falling and this is not inconsistent with a decreasing marginal WTP.

Two payment vehicles are used to assess the effect that a possible increase in backcountry user fees would have: an increase in total trip costs and an increase in the backcountry user fee that is assessed on a per-person-day basis. Recreational users may consider general and unspecified increases in food prices, outfitters fees, travel costs and to some degree user fees as being somewhat beyond their control. On the other hand, an increase in the user fee alone signals a specific policy decision targeted to the recreational activity. It is clear from the comments that many respondents felt, or at least hoped, that their comments would be read by provincial park management. It is possible that many may have felt that a Yes response to a higher user fee may have sent the signal that it would be acceptable for the provincial authorities to do so. Two other results suggest that this may be the case:

- While there is a clear and significant difference in WTP by trip length as measured by the general cost payment vehicle, this is not the case with the user fee payment vehicle.

- Quetico has the lowest per-person-day surplus benefits estimate when estimated with the general cost increase payment vehicle, but the highest estimate when the user fee vehicle is used.

Of the three parks, Quetico visitors incur the highest actual expenditures per trip, but the park has by far the least infrastructure, and users seem to be more satisfied with wilderness conditions. For this reason, we would tend to look more favorably upon the WTP estimates from the total cost increase payment vehicle as representing surplus benefits generated by the resource.

It had been determined during survey development that a benefits measure derived from an increased user fee would likely be influenced by negative attitudes and suspi- cion toward how the province would actually use the revenues generated. Many backcountry users were aware that their backcountry fees were not earmarked for wilderness preservation, and expressed dissatisfaction about it. It has been a policy of the provincial government that revenues earned from specific uses of government-owned resources cannot be earmarked for the support of or reinvestment into the same resource. Provincial park user fees currently go into general revenues, and park budgets are justified annually on the basis of expected operating expenses. Operating expenses tend to be greater for park uses that are much more user-intensive than the use of the wildernesszoned backcountry canoe routes. Wilderness groups and private outfitters have publicly questioned the incentives parks have to emphasize intensive use and construction of infrastructure over more ecologically benign "wilderness" use.

While we fully anticipated that there should be some payment vehicle bias, the extent of this bias is also of interest in the context of a current policy debate regarding reduced park budgets and the need for operating revenues. The recently proposed Parks Ontario program has been generally supportive of a trend to allow park management to set fees independently and to earmark a portion of their revenues for specific purposes, in the interest of providing decentralized incentives to manage parks more efficiently and increase revenues. It is clear from this study that there is a willingness to support the province's efforts to protect wilderness areas. However, if the Parks Ontario program is to be implemented, people may generally be more supportive of backcountry fee increases only if revenues are earmarked specifically for wilderness preservation.

\section{NOTES}

${ }^{1}$ The wilderness canoeists in the study rarely took more than one or two wilderness trips in a season. ${ }^{2}$ The decision of whether to use the mean or median as a measure of value has received considerable attention in the literature. Hanneman (1984) advocates the use of the median as a measure of 
economic value because it is more robust to the influences of outliers and extreme values sometimes encountered with natural resource-based goods. Other authors argue that the mean is the preferred welfare measure. They posit that extreme values are legitimately held by those who value the resource the most.

${ }^{3}$ An attempt was made to access marginal values per trip-day directly as opposed to by average values per trip length from model 3 . This regression (not shown) did not fit the data well and $t$-statistics were insignificant on the estimated coefficients for all but third- and fourth-day effects. These results most likely stemmed from the fact that the model treated daily marginal values as equivalent across trips of differing lengths. This model essentially forced equivalent marginal values for the fourth day of a four-day canoe trip and the fourth day of a ten-day trip, thus ignoring the diversity in time constraints and preferences that compel canoeists to choose different trip lengths. While the results from model 3 evaluate the declines in the value of a trip as the full trip value averaged to a per-day basis, a declining marginal daily value can be inferred by the falling average value.

${ }^{4}$ The WTP values for 14-day and 15-19-day trip lengths in Table 6 are estimated using very small sample sizes (22 and 27 , respectively) and the standard errors are very high. So although they appear very odd, they are essentially meaningless. One respondent on a 14-day trip who said No to a $\$ 20$ bid value would appear as an extreme value on the lower tail, for example, and have a disproportionate effect on the estimate. However, as stated above, we can find no compelling reason to delete any of the data as outliers.

${ }^{5}$ Kanninen (1995) has pointed out that unbiasedness results if the sample includes no protest bids or outliers at the tails of the distribution, since outliers on the tails have a disproportionate effect on the estimated mean. Since it is often a judgment call as to whether an extreme bid is a protest or reflects legitimately held values, Kanninen points out that for reasons of unbiasedness, as well as for efficiency, it is desirable to mass bid values more heavily near the mean and less so near the tails.

${ }^{6}$ It was decided that it would not have been instructive to simply partition the set into three nonoverlapping sets according to the months in which the bid amount distributions were altered. There are several reasons why we did not do this. Firstly, this may have introduced systematic bias due to the months the trips were taken (for example, May and early June is blackfly season, reasonably making WTP for these trips less than those of later in the season). Secondly and most importantly, the actual updates were done to gather a cumulative data set that had the desired distributional properties. Thus, the later months had bid amounts massed on the "higher end" but when taken together over the entire season, the lower tail still had the higher mass of bid amounts. Updates were done sequentially to augment already collected data. The offer amount distributions for individual months did not, nor were they meant to be, taken as standalone subsets of the data. Finally, the number of observations differed between the monthly partitions, making comparisons of efficiency gains less obvious.

${ }^{7}$ Park, Loomis and Creel (1991) developed this method of estimating confidence intervals for WTP estimates using Monte Carlo simulations from the estimated parameters.

${ }^{8}$ While this is true in theory, Kanninen (1995) acknowledges that applied "researchers cannot identify optimal bid values before administering their surveys. In the absence of reliable prior information about the parameter values, this rule of thumb is intended only to prevent researchers form feeling the need to cover extreme ranges of the WTP distribution." (p. 123)

${ }^{9}$ The general formula used for calculating the aggregate net willingness-to-pay is given by: Aggregate Net WTP for__ Park in 1993 for Canoeists Who Did Trips of $>2$ Nights $=($ Number of Canoeing Parties)*(Average Party Size)* (Average Trip Length)*(Average Value of Net Benefit per Person per Day)

\section{REFERENCES}

Alberini, Anna. 1995. Optimal designs for discrete choice contingent valuation surveys: Singlebound, double bound, and bivariate models. Journal of Environmental Economics and Management 28: 287-306.

Arrow, K, R. Solow, P. R. Portney, E. E. Leamer, R. Radner and H. Schuman. 1993. Report of the NOAA panel on contingent valuation. Federal Register 58: 4601-14.

Boyle, K. L., M. P. Welsh and R. C. Bishop. 1988. Validation of empirical measures of welfare change: Comment. Land Economics 64: 94-98.

Cooper, J. C. 1993. Optimal bid selection for dichotomous choice contingent valuation surveys. Journal of Environmental Economics and Management 24: 25-40.

Duffield, John W. and David Patterson. 1991. Inference and optimal design for a welfare measure in dichotomous choice contingent valuation. Land Economics 67 (2): 225-39. 
Hanneman, Michael W. 1984. Welfare evaluations in contingent valuation experiments with discrete responses. American Journal of Agricultural Economics (August): 332-41.

Kanninen, Barbara J. and Bengt Kristršm. 1993. Sensitivity of willingness-to-pay estimates to bid design in dichotomous choice valuation models: Comment. Land Economics 69 (2): 199-202.

Kanninen, Barbara. 1995. Bias in discrete response contingent valuation. Journal of Environmental Economics and Management 28: $114-25$
Park, Timothy, John Loomis and Michael Creel. 1991. Confidence intervals for evaluating benefits estimates from dichotomous choice contingent valuation studies. Land Economics 67 (1): 64-73.

Valla, Andreana. 1994. Benefits of wilderness canoeing and camping at Quetico provincial park: an application of a zonal travel cost model. Msc thesis. Guelph: University of Guelph. 